Artigo

\title{
Bancos de Dados Meteorológicos: Análise dos Metadados das Estações Meteorológicas no Estado de Santa Catarina, Brasil
}

\author{
Luiz Fernando de Novaes Vianna ${ }^{1 *}$, Edenir Bagio Perin ${ }^{2}$, Wilian da Silva Ricce ${ }^{1}$, \\ Angelo Mendes Massignan ${ }^{1}$, Cristina Pandolfo ${ }^{1}$ \\ ${ }^{1}$ Centro de Informações de Recursos Ambientais e de Hidrometeorologia de Santa Catarina, \\ Empresa de Pesquisa Agropecuária e Extensão Rural de Santa Catarina, \\ Florianópolis, SC, Brasil. \\ ${ }^{2}$ Programa de Pós-Graduação em Geografia, Centro de Filosofia e Ciências Humanas, \\ Universidade Federal de Santa Catarina, Florianópolis, SC, Brasil.
}

Recebido: 2 de Outubro de 2015 - Aceito: 18 de Maio de 2016

\begin{abstract}
Resumo
O objetivo desse trabalho foi avaliar os metadados das estações meteorológicas no estado de Santa Catarina com base nas recomendações da Organização Mundial de Meteorologia (OMM). Os metadados das estações foram obtidos, via internet, nos sítios do Instituto Nacional de Meteorologia (INMET), do Agritempo, da Agência Nacional de Águas (ANA) e diretamente da Empresa de Pesquisa Agropecuária e Extensão Rural de Santa Catarina (Epagri). Os resultados demonstraram que os metadados disponíveis para as estações meteorológicas que cobrem o Estado de Santa Catarina não atendem integralmente às recomendações da WMO. Foram identificados problemas nos processos de codificação e georreferenciamento das estações, no cadastro em relação à responsabilidade institucional pelas estações, problemas de inconsistência cadastral entre estações presentes em mais de um banco de dados e incertezas relacionadas à posição geográfica das estações.
\end{abstract}

Palavras chave: climatologia, meteorologia, georreferenciamento, cadastro.

\section{Meteorological Databases: Metadata Analysis of the Weather Station Network in the Santa Catarina State, Brazil}

\begin{abstract}
The objective of this paper was to evaluate the weather stations metadata in Santa Catarina state based on the recommendations of the World Meteorological Organization (WMO). Metadata available at websites of the Instituto Nacional de Meteorologia (INMET), the Agritempo, the Agência Nacional de Águas (ANA) and the Empresa de Pesquisa Agropecuária e Extensão Rural de Santa Catarina (Epagri) were evaluated. The results showed that the metadata available for the weather stations that cover the state of Santa Catarina does not fully meet the OMM recommendations. There are problems in the stations coding and geo-referencing. There are registration problems regarding institutional responsibility for the stations and there are cadastral inconsistency between stations present in more than one database. There are also uncertainties related to the geographical position of the stations.
\end{abstract}

Keywords: climatology, meteorology, georeferencing, register.

\section{Introdução}

Os bancos de dados meteorológicos são planejados para receber, armazenar, processar e disponibilizar dados e informações das diversas variáveis meteorológicas (ex. precipitação pluviométrica, temperatura do ar, umidade relativa do ar ou radiação). Os dados meteorológicos são gerados localmente, por meio de estações meteorológicas convencionais ou automáticas, ou remotamente por intermédio de sensores orbitais, aerotransportados ou ainda por sistemas de radar. Com o desenvolvimento tecnológico dos sistemas de posicionamento global (GPS) e sistemas de

Autor de correspondência: Luiz Vianna, vianna@epagri.sc.gov.br. 
informações geográficas (SIG), é cada vez mais comum analisar esses dados através de superfícies contínuas de distribuição espacial das variáveis, normalmente representadas em mapas cloropléticos ou através de isolinhas (Castro, et al., 2010; Silva, et al., 2011; Jones, et al., 2012; Lucas, et al., 2013; Camera, et al., 2014). Essas superfícies são geradas diretamente pelo processamento dos dados dos sensores remotos ou através de análise de regressão ou interpolação dos dados das redes de estações.

O processamento e a análise de múltiplas superfícies contínuas de variáveis meteorológicas permitem, por exemplo, elaborar zoneamentos de áreas potenciais para agricultura (Cunha et al., 2001; Ricce et al., 2014; Massignam, et al., 2014), identificar áreas expostas a riscos climáticos (Herrmann, 2006) e fazer previsão do tempo e estudos climáticos. Sites especializados em previsão do tempo e climatologia, como o do Serviço Nacional de Previsão do Tempo dos Estados Unidos (NOAA, 2015), o do Instituto Nacional de Meteorologia do Brasil (INMET, 2015) e o do Centro de Previsão de Tempo e Estudos Climáticos CPTEC do Brasil (INPE/CPTEC, 2015), além da mídia televisiva (CLIMATEMPO, 2015), se utilizam dos mapas para representar variações espaciais de temperatura e precipitação na previsão do tempo. Os dados das estações meteorológicas atualmente disponibilizados pelas instituições oficiais vêm sendo utilizados, ainda, para gerar produtos e informações climatológicas para o Brasil (Ramos, et al., 2009), para a Região Sul (Wrege, et al., 2011) e para Santa Catarina (Pandolfo, et al., 2002).

No caso dos mapas gerados por interpolação ou por equações de regressão é fundamental conhecer o processo de geração dos dados meteorológicos pontuais. Parte desse conhecimento está armazenada nos metadados das estações meteorológicas, compostos pelas informações ou parâmetros auxiliares aos dados coletados (WMO, 2007), como a identificação da estação, a localização e a precisão geográfica, a instituição responsável pela instalação e manutenção da estação e o objetivo da estação. Além das informações relacionadas ao processo de obtenção dos dados, como informações técnicas dos sensores e a periodicidade em que os dados são coletados. No caso específico das redes de estações meteorológicas, os metadados relacionados à localização espacial (latitude, longitude e altitude) dos sensores são cruciais para a geração de superfícies contínuas (Perin et al., 2015).

A Organização Mundial de Meteorologia (World Meteorological Organization - WMO) possui recomendações para as instituições usuárias e mantenedoras das redes de estações meteorológicas identificarem e gerenciarem suas estações por meio de códigos (WMO, 2014) e protocolos de instalação e manutenção (WMO, 2007; WMO, 2008). Os metadados cadastrais devem estar disponíveis aos usuários de forma padronizada, clara e acessível (WMO, 2003). Adotar um critério de codificação, garantir a precisão mínima na localização geográfica dos instrumentos instalados nas estações e conhecer as instituições responsáveis pela sua instalação, manutenção e operação são as condições primárias para garantir a qualidade dos dados necessários para a geração de superfícies contínuas.

Os metadados gerenciais também são importantes para auxiliar na escolha do conjunto de estações a ser trabalhado em função dos objetivos do uso dos dados. O Guia Para o Sistema de Observação Global (WMO, 2007) sugere que as instituições devem manter uma lista atualizada das estações sob sua responsabilidade, fornecendo, além dos metadados cadastrais, informações sobre o objetivo da estação, seus aparelhos de medição, os métodos de coleta dos dados meteorológicos, a periodicidade de armazenamento e transmissão, as datas dos períodos de manutenção e operação e das séries históricas. Informações complementares sobre algumas características físicas do entorno da estação (relevo, cobertura vegetal e construções) também fazem parte dos metadados gerenciais.

Assim, o objetivo desse trabalho é avaliar os metadados das estações meteorológicas em Santa Catarina com base nas recomendações da WMO (WMO, 2007; WMO, 2014). Os objetivos específicos são: identificar a presença dos metadados sugeridos pela WMO (WMO, 2007) nos bancos de dados do Instituto Nacional de Meteorologia (INMET), do Agritempo, da Agência Nacional de Águas (ANA) e da Empresa de Pesquisa Agropecuária e Extensão Rural de Santa Catarina (Epagri); avaliar a posição geográfica, sua referência, o formato das coordenadas, a precisão e as exigências em relação ao cadastro da altitude das estações e seus instrumentos; avaliar os códigos e critérios de codificação das estações em comparação ao padrão da WMO (WMO, 2014) e investigar a correspondência dos metadados cadastrais presentes nos bancos do INMET, do Agritempo, da ANA e da Epagri.

\section{Materiais e Métodos}

\subsection{Organização dos metadados}

Os metadados das estações convencionais e automáticas do INMET, do Agritempo, da ANA e da Epagri foram obtidos no dia 29/07/2015. Foram levantados apenas os metadados das estações pertinentes ao Estado de Santa Catarina. O acesso aos metadados foi feito via internet nos respectivos sítios e, no caso de indisponibilidade de acesso público, eles foram obtidos através da solicitação formal à instituição mantenedora do banco de dados.

$\mathrm{O}$ acesso aos metadados cadastrais das estações do INMET foi feito por meio do sistema de mapa das estações convencionais e automáticas (INMET, 2015²), do sistema de mapa das estações automáticas (INMET, 2015 $5^{3}$ ) e do sistema de mapa das estações convencionais (INMET, $2015^{4}$ ). Os metadados oriundos dos três sistemas de mapas foram comparados e organizados manualmente em uma tabela no Excel. Os demais metadados do INMET foram obtidos em documentos disponíveis no sítio e no Banco de 
Dados Meteorológicos para Ensino e Pesquisa-BDMEP (INMET, 2015 $5^{5}$.

Os metadados cadastrais das estações do Agritempo foram obtidos em forma de tabela, utilizando uma consulta para filtrar apenas os metadados das estações de Santa Catarina (AGRITEMPO, 2015). O sítio do Agritempo não disponibiliza os metadados gerenciais, pois não possui rede de estações.

Os metadados cadastrais das estações da ANA foram obtidos com o download do banco de dados no Hidroweb (ANA, 2015). Nesse banco estão os metadados de todas as estações hidrológicas (fluviométricas e pluviométricas) do Brasil. Para esse trabalho foram selecionadas apenas as estações pluviométricas de Santa Catarina. Informações complementares sobre os metadados das estações da ANA foram obtidas no inventário das estações pluviométricas (ANA, 2009) e nas especificações técnicas das plataformas de coleta de dados - PCD (ANA, 2011).

Os metadados das estações da Epagri não possuem acesso público através do sítio (Epagri/Ciram, 2015), por isso foram obtidos diretamente com o Centro de Informações Ambientais e de Hidrometeorologia (Epagri/Ciram). Os metadados foram fornecidos em uma planilha Excel gerada diretamente a partir do banco de dados das estações meteorológicas. Apesar da indisponibilidade de acesso direto, tanto os produtos gerados pelas estações quanto suas séries históricas podem ser solicitados através de formulários específicos no sítio da Epagri/Ciram.

\subsection{Identificação da presença dos metadados previstos no guia da WMO (2007)}

Os metadados das estações disponibilizados pelas quatro instituições foram levantados e comparados com os metadados previstos pela WMO (2007). Em uma planilha foram tabuladas a presença ou ausência dos seguintes metadados para as quatro instituições: a) nome e código da estação; b) coordenadas geográficas em WGS84 com precisão mínima de 0,001 graus; c) altitude da estação (em metros) e altitude do barômetro acima do nível do mar; d) nível do geopotencial; e) categoria da estação e do programa de observação; f) o tempo em que as observações sinóticas são feitas e comunicadas; g) breve descrição da topografia circundante; h) exposição do instrumento, altura acima do solo dos termômetros, pluviômetros e anemômetros; i) histórico da estação: data de início das observações regulares, transferências, interrupções nas observações, mudanças na identificação da estação e quaisquer outras alterações substanciais introduzidas no programa de observação; j) nome da organização ou instituição responsável e k) outras informações necessárias à conclusão dos relatórios climáticos.

Além da verificação da presença ou ausência, sobre os metadados geográficos, fez-se uma busca pelas informações relacionadas ao processo de georreferenciamento (sistema de referência, método de georreferenciamento, precisão e medição da altitude das estações e dos instru- mentos). Também foi verificada a precisão das coordenadas em relação ao formato numérico (quantidade de casas decimais). Tanto as coordenadas disponíveis em graus decimais quanto aquelas apresentadas em graus minutos e segundos foram contabilizadas para gerar uma estatística em relação à precisão.

\subsection{Avaliação dos códigos e dos processos de codificação das estações}

Para verificar os códigos e critérios de codificação das estações foram consultados manuais, normas e legislação, além de consultas presenciais e contatos por telefone com os responsáveis pela manutenção dos bancos de dados do INMET, da ANA e da Epagri. O código das estações de cada banco de dados foi comparado com o padrão de codificação da WMO (WMO, 2014).

\subsection{Avaliação da correspondência cadastral entre os bancos de dados}

Para avaliar a correspondência cadastral (códigos, nomes, coordenadas geográficas, altitude e nomes das instituições responsáveis) entre os bancos de dados do INMET, do Agritempo, da ANA e da Epagri, foi organizada uma planilha para cada instituição contendo os seguintes campos: código da estação; código complementar; nome da estação; código da instituição responsável; nome da instituição responsável; latitude em graus decimais; longitude em graus decimais; e altitude em metros.

Foi feita uma análise exploratória nos metadados cadastrais para avaliar as possibilidades de duplicidade entre estações. Nas planilhas foram verificados o número de estações existentes no banco de dados de cada instituição e a quantidade de estações sob responsabilidade das demais instituições.

As estações foram espacializadas no SIG ArcGis 10.2, com base nas coordenadas disponíveis nos metadados de cada instituição. Foram criadas quatro camadas (layers) de pontos, uma para as coordenadas disponíveis nos metadados do INMET, uma para as coordenadas do Agritempo, uma para as coordenadas da ANA e uma para as coordenadas da Epagri (Fig. 1).

Os metadados das instituições foram comparados de forma pareada partindo-se do menor banco de dados para o maior. A comparação pareada foi feita através dos códigos, dos códigos complementares e da posição geográfica. Foi verificada a responsabilidade pelas estações, atribuída a cada instituição. Os resultados foram organizados em três matrizes $4 \times 4$, comparativas entre as instituições, onde foram computados o número de estações sob responsabilidade de cada instituição, o número de estações com códigos coincidentes e o número de estações com mesma posição geográfica.

A comparação pelos códigos e códigos complementares foi feita através da junção (join) entre o par de planilhas das instituições com objetivo de identificar as estações 


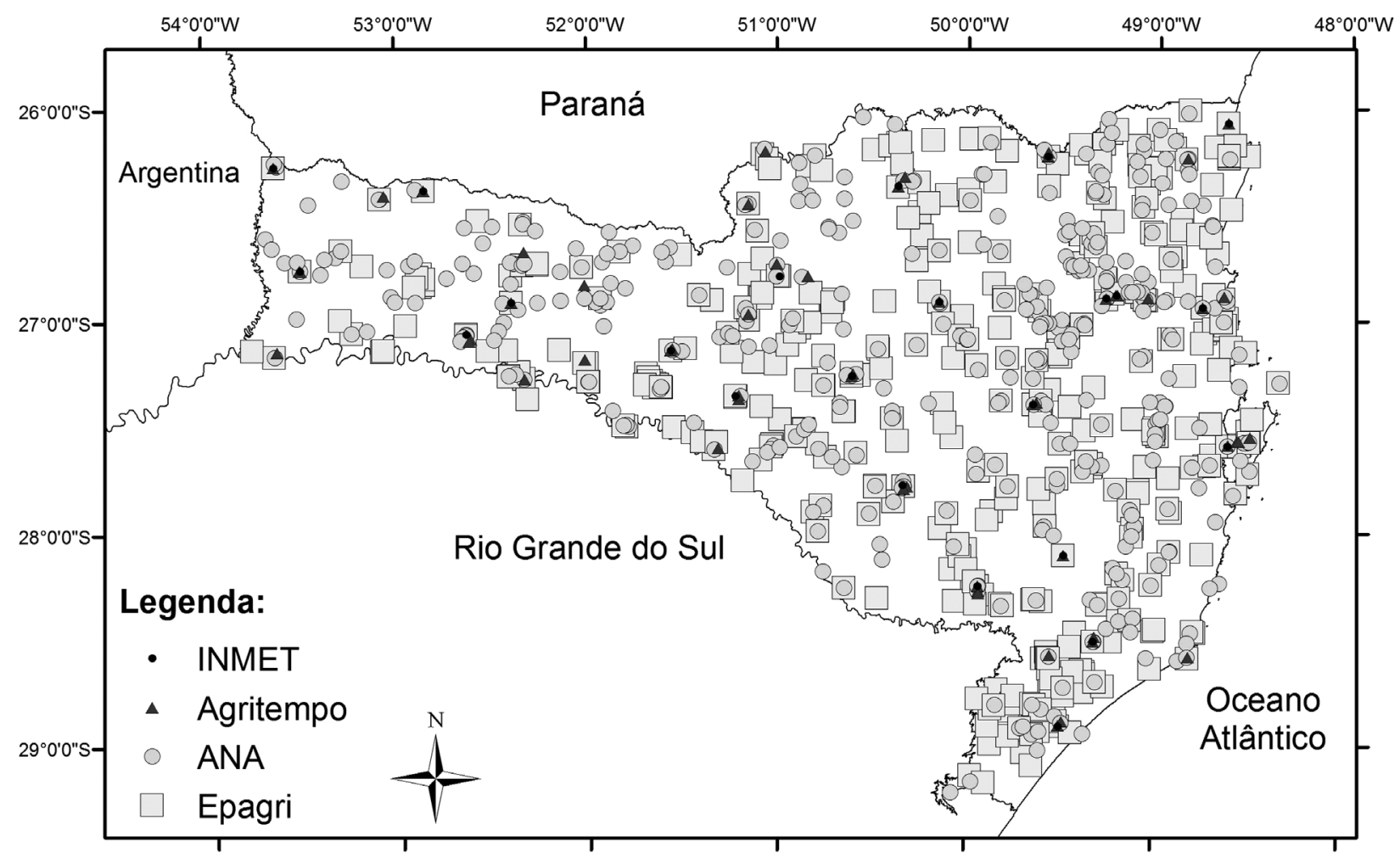

Figura 1 - Mapa das estações meteorológicas do INMET, do Agritempo, da ANA e da Epagri, de acordo com as coordenadas disponíveis nos respectivos metadados para o Estado de Santa Catarina.

com códigos iguais e verificar a coincidência dos demais metadados.

A avaliação da coincidência da posição geográfica das estações entre os bancos foi feita através de uma análise de vizinhança, utilizando a ferramenta de junção espacial (spatial join). Primeiro foram avaliadas as estações com a posição geográfica idêntica entre os quatro bancos de dados. Em seguida foi definido um raio máximo de 2,5 km dentro do qual um conjunto de estações oriundas de bancos distintos poderia ser considerado como a mesma estação. $\mathrm{O}$ valor de $2,5 \mathrm{~km}$ corresponde ao valor próximo ao dobro da precisão de um centésimo de grau $(0,01)$ ou $1,2 \mathrm{~km}$, necessária para abranger $95 \%$ das estações de todos os bancos. Isso porque $95 \%$ das estações possuem coordenadas em graus decimais com pelo menos duas casas decimais.

Para representar as divergências encontradas e analisar os problemas que essas divergências podem causar na geração de superfícies contínuas foram utilizados, como exemplos, os casos das estações de Campos Novos e de São Joaquim. As posições das estações nominadas como estação de Campos Novos em todos os bancos foram comparadas para verificar disparidades de responsabilidade, codificação e posicionamento geográfico. As posições foram comparadas também com as imagens do aerolevantamento do Estado de Santa Catarina (SDS, 2012) para verificar as distâncias em relação ao local exato da estação, considerando que o aerolevantamento atende à escala planimétrica de 1:2.000 (SDS, 2012).
Para demonstrar a influência que a diferença de localização pode causar na variação de altitude foi utilizada a estação do INMET de São Joaquim (Código 83920). Essa estação foi escolhida por estar presente em todos os bancos e apresentar coincidência cadastral tanto do código quanto da instituição responsável. A localização geográfica dada pelas coordenadas disponíveis em cada um dos bancos foi comparada ao modelo digital de elevação de Santa Catarina (SDS, 2012). Para quantificar a variação de altitude dada pela diferença das coordenadas foi feita uma estatística por zona utilizando uma área formada pelo raio de $2,5 \mathrm{~km}$ no entorno da posição das estações.

\section{Resultados e Discussão}

Na Fig. 2 está esquematizado o modelo de pertinência das estações contidas nos bancos de dados das quatro instituições.

Em Santa Catarina o INMET possui apenas estações próprias. O Agritempo não possui estações, apenas se utiliza das estações cuja responsabilidade ele atribui ser do INMET e da Epagri. A ANA possui estações próprias, mas também utiliza estações que considera ser de responsabilidade do INMET, da Epagri e de outras instituições. A Epagri possui estações próprias e se utiliza de estações cuja responsabilidade a empresa afirma ser do INMET, da ANA e de outras instituições. 


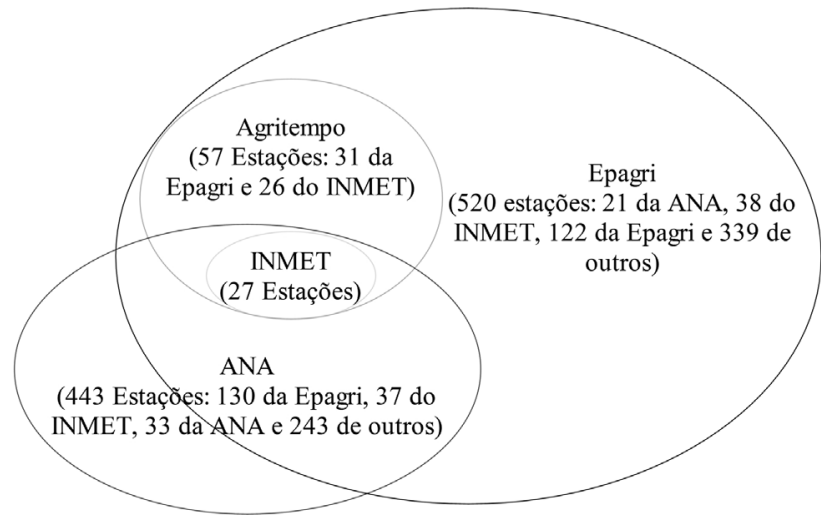

Figura 2 - Modelo provável de pertinência das estações meteorológicas existentes nos bancos de dados do INMET, do Agritempo, da ANA e da Epagri no Estado de Santa Catarina.

\subsection{Identificação da presença dos metadados previstos no guia da WMO (2007)}

Os metadados cadastrais das estações de Santa Catarina (Tabela 1) estão parcialmente presentes nas quatro instituições.

O Guia de Instrumentos e Métodos de Observação Meteorológica (WMO, 2008) indica que a posição geográfica das estações deve ser referenciada pelo datum World
Geodetic System 1984 (WGS-84) e o modelo gravitacional Earth Geodetic Model 1996 (EGM96), devendo ser conhecida a precisão das medidas. O documento indica também que deve ser disponibilizada a altura do pluviômetro a partir da altitude do ponto onde ela está instalada. Caso não exista pluviômetro, deverá ser apresentada a altura do termômetro até a base da estação; não existindo nem termômetro nem pluviômetro, a medida média do terreno local imediato. Se a estação apresentar dados de pressão, a altitude do barômetro deve ser informada separadamente.

As alturas dos instrumentos acima do solo e as informações sobre o processo de georreferenciamento das estações (método de obtenção das coordenadas; sistema de referência; precisão e cálculo de altitude) não estão disponíveis nos sítios de nenhuma das instituições. Isso é um problema para o uso dos dados na geração de superfícies contínuas. O desconhecimento da precisão do posicionamento geográfico das estações compromete os estudos em climatologia que utilizam análise de regressão para estimar temperaturas em função de latitude, longitude e altitude (Perin, et al., 2015). Alvares, et al. (2013) eliminaram mais de $50 \%$ das estações meteorológicas disponíveis em seu estudo de modelagem da temperatura média mensal no Brasil por falta de informação nos metadados, pouca con-

Tabela 1 - Disponibilidade dos metadados sugeridos pela WMO (WMO, 2007) nos bancos do INMET, do Agritempo, da ANA e da Epagri no Estado de Santa Catarina.

\begin{tabular}{|c|c|c|c|c|}
\hline Metadados & INMET & Agritempo & ANA & Epagri \\
\hline \multicolumn{5}{|l|}{ Cadastrais } \\
\hline Nome da estação & $\mathrm{X}$ & $\mathrm{X}$ & $\mathrm{X}$ & $\mathrm{X}$ \\
\hline Código da estação & $\mathrm{X}$ & $\mathrm{X}$ & $\mathrm{X}$ & $\mathrm{X}$ \\
\hline Coordenadas geográficas & $\mathrm{X}$ & $\mathrm{X}$ & $\mathrm{X}$ & $\mathrm{X}$ \\
\hline Informação sobre o Datum & - & - & - & - \\
\hline Precisão mínima de 0,001 graus & - & - & - & $\mathrm{X}$ \\
\hline Altitude da estação em metros & $\mathrm{X}$ & $\mathrm{X}$ & $\mathrm{X}$ & $\mathrm{X}$ \\
\hline Altura acima do solo dos termômetros & - & - & - & - \\
\hline Altura acima do solo dos pluviômetros & - & - & - & - \\
\hline Altura acima do solo dos anemômetros & - & - & - & - \\
\hline Elevação do barômetro acima do nível do mar & - & - & - & - \\
\hline Nível do geopotencial & - & - & - & - \\
\hline \multicolumn{5}{|l|}{ Gerenciais } \\
\hline Categoria da estação & - & - & $\mathrm{X}$ & $\mathrm{X}$ \\
\hline Categoria do programa de observação & - & - & $\mathrm{X}$ & - \\
\hline Data de início das observações regulares & $\mathrm{X}$ & - & - & $\mathrm{X}$ \\
\hline O tempo em que as observações são feitas e comunicadas & $\mathrm{X}$ & - & $\mathrm{X}$ & $\mathrm{X}$ \\
\hline Breve descrição da topografia circundante & - & - & - & - \\
\hline Controle de transferências dos equipamentos & - & - & - & - \\
\hline Mudanças de nome ou alterações no programa de observação & - & - & - & - \\
\hline Nome da organização ou instituição responsável & * & $\mathrm{X}$ & $\mathrm{X}$ & $\mathrm{X}$ \\
\hline Outras informações necessárias à conclusão dos relatórios & $\mathrm{X}$ & - & $\mathrm{X}$ & $\mathrm{X}$ \\
\hline
\end{tabular}

(X) presente; (-) ausente; (*) não procede. 
fiabilidade no posicionamento geográfico delas e a não homogeneidade das séries históricas.

Mesmo sem os metadados acerca do processo de georreferenciamento, foi possível constatar que algumas estações podem apresentar erros de posicionamento horizontal (latitude e longitude) de até $111,12 \mathrm{~km}$, considerando apenas o formato das coordenadas disponíveis nos metadados (Tabela 2). A WMO define a precisão mínima necessária para o georreferenciamento de uma estação em 0,001 graus decimais (WMO, 2008) ou $111,12 \mathrm{~m}$, o que permite gerar mapas que atendam com segurança à escala 1:250.000, classe $\mathrm{A}$, considerando o Padrão de Exatidão Cartográfica (PEC) do Brasil (Brasil, 1984), que é de $125 \mathrm{~m}$ para essa escala.

A Epagri é a única instituição cujas coordenadas estão em graus, minutos e segundos, o que corresponde a uma precisão máxima de $30,87 \mathrm{~m}$. Isso ocorre porque em 2012 foi feito um recadastramento das estações. Na época foram recadastradas 420 coordenadas, das quais $37,8 \%$ foram atualizadas através das imagens disponíveis no Google Earth e $62,2 \%$ foram atualizadas em campo com uso de GPS de navegação. Nesse processo foram atualizadas as coordenadas de algumas estações sob responsabilidade do INMET e da ANA, porém as novas coordenadas não foram repassadas para aquelas instituições.

Apesar do ajuste nas coordenadas, essas informações não estão disponíveis no sítio da Epagri, mas estão registradas nos metadados das estações. Das atuais 520 estações presentes no banco de dados da Epagri, 68\% correspondem àquelas que tiveram as coordenadas recadastradas em 2012, as demais ou foram instaladas depois ou não foram recadastradas, mas mesmo assim suas coordenadas estão disponíveis no formato adotado pela instituição (GGMMSS).

As coordenadas das estações do INMET estão disponíveis no site em três hyperlinks distintos. No primeiro estão disponíveis as coordenadas de todas as estações automáticas e convencionais, com precisão de duas casas decimais (INMET, 2015²). Nos outros dois estão disponíveis separadamente as coordenadas das estações automáticas $\left(\right.$ INMET, $2015^{3}$ ) e das estações convencionais (INMET, $2015^{4}$ ), com precisão que varia de uma a seis casas decimais. Algumas dessas estações compõem o conjunto das
411 estações do INMET utilizadas para gerar as normais climatológicas do Brasil (Ramos, et al., 2009) cujas coordenadas estão publicadas em graus e minutos.

Da mesma forma que ocorre com os metadados cadastrais, nenhuma das quatro instituições disponibiliza os metadados gerenciais integralmente. As datas de início de operação e o controle de transferência dos equipamentos estão incompletos e sem eles não é possível saber se houve mudança de localização de uma estação, se houve troca de sensor, se a frequência de coleta dos dados foi alterada em uma determinada data ou mesmo conhecer os períodos de operação em que a série histórica foi coletada de maneira homogênea.

\subsection{Avaliação dos códigos e dos processos de codificação das estações}

Para identificar uma estação, o manual de códigos internacionais (WMO, 2014) determina a utilização de um código numérico de cinco dígitos (IIiii), composto pelo número do bloco ou indicador regional (II) e o número da estação (iii). O número do bloco define a zona em que está localizada a estação de medição. Para a América do Sul, identificada como região III, o manual estabelece a sequência entre 80001-88998. Os códigos indicadores da estação (iii) correspondentes ao indicador regional dividido em várias faixas, por um ou vários graus de latitude. Quando possível, a codificação das estações situadas dentro de uma mesma faixa deve ser crescente de oeste para leste e o primeiro dígito dos três números indicadores da estação, crescente de norte para sul.

Apenas o INMET segue o critério de codificação definido pela WMO (WMO, 2014). No estado de Santa Catarina as 27 estações estão codificadas no bloco 3 para a América do Sul, ocupando as faixas iniciadas pelos números 83 (estações convencionais) e 86 (estações automáticas) do código (IIiii). Apesar disso, a contínua necessidade de expansão da rede forçou o instituto a utilizar um código auxiliar para as estações automáticas composto por uma letra e três dígitos numéricos (Xiii). O código auxiliar não segue os padrões estabelecidos pela WMO (WMO, 2014) e foi adotado porque a expansão da rede preencheu todos os códigos nas faixas disponibilizadas pela WMO para o Brasil.

Tabela 2 - Porcentagem do número de estações por formato e valor de precisão das coordenadas geográficas disponíveis nos bancos de dados do INMET, Agritempo, ANA e Epagri no Estado de Santa Catarina.

\begin{tabular}{|c|c|c|c|c|c|c|c|c|}
\hline Formato & $1^{\circ}$ & $0^{\circ}, 1$ & $0^{\circ}, 01$ & $1^{\circ}, 001$ & $0^{\circ}, 0001$ & $0^{\circ}, 00001$ & $0^{\circ}, 000001$ & $00^{\circ} 00^{\prime} 01^{\prime \prime}$ \\
\hline Precisão (m) & 111.120 & 11.112 & $1.111,2$ & 111,12 & 11,112 & 1,1112 & 0,11112 & 30,87 \\
\hline INMET & $3,7 \%$ & $7,4 \%$ & $7,4 \%$ & & $81,5 \%$ & & & \\
\hline Agritempo & $3,5 \%$ & $26,3 \%$ & $40,4 \%$ & $29,8 \%$ & & & & \\
\hline ANA & $1,6 \%$ & $7,9 \%$ & $10,2 \%$ & $5,2 \%$ & $75,2 \%$ & & & \\
\hline Epagri & & & & $100,0 \%$ & & & & \\
\hline Total & $0,9 \%$ & $4,9 \%$ & $6,5 \%$ & $4,0 \%$ & $32,0 \%$ & $0,0 \%$ & $2,1 \%$ & $49,7 \%$ \\
\hline
\end{tabular}


O excesso de estações em comparação ao número de códigos disponíveis é um problema mundial e a WMO está trabalhando em um novo sistema. O WMO Integrated Global Observing System-WIGOS (WMO, 2015) apresenta uma proposta que vai além da ampliação do número de códigos. Trata-se de um novo padrão de metadados que atenderá às atuais demandas de expansão das redes de monitoramento e ao desenvolvimento tecnológico. A apresentação oficial desse novo sistema aconteceu em junho de 2015, no Congresso Mundial de Meteorologia, em Geneva (WMO 2015 ${ }^{2}$ ).

Para as estações do INMET, o Agritempo adota os códigos do próprio INMET. Já para as estações da Epagri, os códigos não estão disponíveis nos metadados.

A codificação das estações adotada pela ANA não atende aos padrões da WMO, pois está regulamentada pelo Decreto ${ }^{\circ} 77.410$, de 12 de abril de 1976 (Brasil, 1976) e pela Portaria $\mathrm{n}^{\circ}$ 447, de 20 de abril de 1976 (Brasil, 1976²). A Portaria $n^{\circ} 447$ define que as estações devem ser codificadas, de acordo com a sua localização, em estações "nos cursos d'água" (fluviométricas) e "fora dos cursos d'água" (pluviométricas). Essa separação faz com que a codificação esteja associada ao equipamento de medição ao invés da localização geográfica da estação. Com isso, uma única estação "localizada dentro de um curso d'água" (fluviométrica) e que tenha um pluviômetro ou pluviógrafo instalado conjuntamente, apresenta dois códigos - um para o coletor de dados do rio e outro para o coletor de dados de precipitação - em um único par de coordenadas geográficas.

A codificação utilizada pela Epagri é feita de forma sequencial e está subdividida nos seguintes conjuntos: estações convencionais meteorológicas de 0 a 1000; estações automáticas: acima de 1001; estações hidrológicas e agrometeorológicas acima de 2000. Para as estações oriundas do banco de dados da ANA são mantidos os códigos de origem. As estações importadas do banco de dados do INMET são identificadas com códigos entre 1500 e 1600 e possuem um campo extra com o código auxiliar das estações automáticas originais (Xiii). Os códigos entre 9000 e 10000 correspondem às estações utilizadas para pesquisa, que em geral são instaladas temporariamente e configuradas para coleta de dados específicos para cada pesquisa.

O fato de as instituições não adotarem um padrão de codificação dificulta sua identificação por meio de uma pesquisa, ainda mais quando essas instituições compartilham as estações em suas bases de dados, cada uma atribuindo um código próprio a uma mesma estação. $\mathrm{O}$ mesmo ocorre em relação às coordenadas geográficas. Como não há informação sobre os protocolos de coleta, validação e disponibilização das coordenadas pelas instituições, os usuários dos dados das estações que fazem suas buscas em mais de uma base, se deparam com estações com códigos e coordenadas distintos, mas que, em muitos casos, são a mesma estação. Há casos ainda de estações com o mesmo código e coordenadas diferentes e estações com coordenadas idênticas e códigos distintos. Esses problemas foram identificados através da avaliação da correspondência cadastral dos quatro bancos.

\subsection{Avaliação da correspondência cadastral entre os bancos de dados}

Nas Tabelas 3, 4 e 5 estão contabilizadas as correspondências cadastrais entre os bancos de dados do INMET, do Agritempo, da ANA e da Epagri. Nelas estão quantificados o total de estações cadastradas em cada banco e o número de estações com correspondência de responsabilidade pela manutenção de estações (Tabela 3), códigos (Tabela 4) e coordenadas (Tabela 5).

A correspondência de responsabilidade pela manutenção das estações refere-se à atribuição da responsabilidade pelos dados de uma determinada estação pela instituição mantenedora do banco de dados avaliado.

Tabela 3 - Cruzamento entre o número total de estações nos bancos de dados do INMET, Agritempo, ANA e Epagri e o número de estações com correspondência de responsabilidade pela manutenção das estações no Estado de Santa Catarina.

\begin{tabular}{lcccccc}
\hline \multicolumn{7}{c}{ Correspondência de responsabilidade } \\
\hline & Total & INMET & Agritempo & ANA & Epagri & Outros \\
\hline INMET & 27 & 27 & 0 & 0 & 0 & 0 \\
Agritempo & 57 & 26 & 0 & 0 & 31 & 0 \\
ANA & 443 & 37 & 0 & 33 & 130 & 243 \\
Epagri & 520 & 44 & 0 & 83 & 180 & 339 \\
\hline
\end{tabular}

Tabela 4 - Cruzamento entre o número total de estações nos bancos de dados do INMET, Agritempo, ANA e Epagri e o número de estações com correspondência de códigos.

\begin{tabular}{lcccc}
\hline \multicolumn{5}{c}{ Correspondência de códigos } \\
\hline Total & INMET & Agritempo & ANA & Epagri \\
\hline INMET & 27 & 25 & 6 & 27 \\
Agritempo & 57 & 25 & 7 & 26 \\
ANA & 443 & 6 & 8 & 86 \\
Epagri & 520 & 27 & 26 & 87 \\
\hline
\end{tabular}

Tabela 5 - Cruzamento entre o número total de estações nos bancos de dados do INMET, Agritempo, ANA e Epagri e o número de estações com correspondência de coordenadas geográficas.

\begin{tabular}{lcccc}
\hline \multicolumn{5}{c}{ Correspondência de coordenadas } \\
\hline Total & INMET & Agritempo & ANA & Epagri \\
\hline INMET & 27 & 0 & 0 & 0 \\
Agritempo & 57 & 0 & 3 & 0 \\
ANA & 443 & 0 & 4 & 0 \\
Epagri & 520 & 0 & 0 & 0 \\
\hline
\end{tabular}


A informação correta a respeito da instituição responsável por cada estação é fundamental para que o usuário possa buscar informações adicionais sobre os dados meteorológicos. Mas para isso, além da correta informação sobre o "proprietário" ou "responsável" pela estação, é preciso poder identificá-la de forma rápida e confiável, o que é feito através do código.

O código é o principal identificador de uma estação. Ele é único para cada estação e por isso a WMO é criteriosa no processo de codificação. Mesmo que uma instituição não adote o código da WMO de forma operacional, a norma de organização dos metadados prevê o uso de códigos complementares (WMO, 2003). Esses códigos devem ser fornecidos sempre que uma instituição se utilizar de estações de outra instituição que adote um critério distinto de codificação. Uma vez que haja correspondência de códigos entre bancos distintos, espera-se que os demais metadados cadastrais sejam idênticos em ambos, o que não ocorreu integralmente entre os bancos avaliados (Tabela 4).

As estações cadastradas no banco de dados do INMET apresentaram correspondência de código com os bancos do Agritempo em 92,6\% das estações, com o banco da ANA em 22,2\% e com o banco da Epagri em 100\% das estações. O Agritempo atribuiu a responsabilidade de 26 estações do seu banco ao INMET (Tabela 3), mas apenas 25 apresentaram coincidência de códigos. A estação de código 83925, apesar de apresentar o código padrão do INMET, foi encontrada apenas no banco do Agritempo. A ANA atribui ao INMET a responsabilidade por 37 estações cadastradas em seu banco (Tabela 3), mas apenas seis delas coincidem com o banco do INMET através dos códigos.

As bases do Agritempo e da ANA possuem sete estações com códigos coincidentes. Como o Agritempo não atribui a responsabilidade de nenhuma estação à ANA, essas sete estações pertencem ao INMET. Das 31 estações mantidas no banco do Agritempo sob responsabilidade da Epagri, apenas 26 apresentaram códigos coincidentes com a base da Epagri. Essas estações, no banco da Epagri, constam como sob responsabilidade do INMET. Com isso percebe-se que as estações da base do Agritempo que possuem código são aquelas sob responsabilidade do INMET e que estão presentes também no banco da Epagri e parcialmente no banco da ANA. Já as 31 estações cuja responsabilidade o Agritempo atribui à Epagri não estão codificadas no banco do Agritempo.

A ANA afirma ter em seu banco, 37 estações sob responsabilidade do INMET (Tabela 3), mas apenas 6 estações apresentaram os códigos coincidentes com os códigos da base do INMET (Tabela 4). Apesar de a ANA possuir um critério próprio de codificação das estações, $13,3 \%$ das estações pluviométricas disponíveis no seu banco possuem um código complementar. Entre as estações com código complementar estão 33 do INMET, 22 da Epagri e 4 de outras instituições.
A ANA atribui à Epagri a responsabilidade por 130 estações (Tabela 3). Entre os bancos da ANA e da Epagri há apenas 86 estações com códigos coincidentes (Tabela 4). Dessas, a ANA atribui responsabilidade à Epagri por 47, assume a responsabilidade por duas e atribui responsabilidade por 75 estações a outras instituições. Já a Epagri atribui responsabilidade à ANA por 54 e 32 delas tem a responsabilidade atribuída a outras instituições. Com isso, das 86 estações com códigos coincidentes entre os bancos da ANA e da Epagri, apenas 17 são coincidentes em relação à instituição responsável. Além disso, das 130 estações existentes no banco da ANA sob responsabilidade da Epagri, 83 não possuem códigos coincidentes entre os dois bancos e, portanto, não são identificáveis.

A Epagri, por sua vez, atribui ao INMET a responsabilidade por 44 estações (Tabela 3), mas apenas 27 possuem os códigos coincidentes (Tabela 4). Essa diferença se refere às 17 estações que já foram desativadas pelo INMET e não estão mais disponíveis via internet no sítio do instituto, mas continuam integrando o banco da Epagri com as séries históricas pretéritas.

A Epagri atribui à ANA a responsabilidade por 83 estações cadastradas no seu banco (Tabela 3). O banco da Epagri possui 87 estações com códigos coincidentes com o banco da ANA. Quando o banco da ANA foi comparado com o banco da Epagri, foram encontradas 86 coincidências entre códigos. A diferença aqui está na estação código 2849024, que está duplicada no banco da Epagri. Das 87 estações com códigos coincidentes, 83 estações são consideradas pela Epagri sob responsabilidade da ANA. Já a ANA apresenta nos seus metadados, dentre essas mesmas 83 estações, apenas uma sob sua responsabilidade, além de 37 estações sob responsabilidade da Epagri e 17 estações sob responsabilidade de outras instituições. Com isso, apenas as 17 estações sob responsabilidade de outras instituições possuem códigos e responsabilidades coincidentes entre os dois bancos.

Entre os bancos da ANA e da Epagri existem diferenças significativas de atribuição de responsabilidade em 70 estações com códigos coincidentes, o que torna difícil para o usuário saber a quem recorrer em caso de necessidade por informações mais precisas sobre os dados gerados por elas.

Da mesma forma que o código é o identificador único de uma estação, a sua posição geográfica também deve ser única. Caso uma estação seja transportada para outro local, ou tenha suas coordenadas alteradas por uma medição mais acurada, a WMO orienta que essa mudança seja documentada de forma precisa, para que possa ser interpretada pelo usuário que avalia a homogeneidade dos dados em relação à série histórica (WMO, 2003).

Os dados apresentados na Tabela 5 demonstram que não há correspondência espacial entre os bancos de dados. Mesmo as estações com códigos comuns entre os bancos possuem coordenadas que variam de uma instituição para a outra. A exceção está em três estações do Agritempo que 
coincidem espacialmente com quatro estações da ANA. Isso porque no banco da ANA as estações 2648011 e 2648026 possuem o mesmo par de coordenadas (-26,9; $-48,65)$, tendo a primeira a responsabilidade atribuída ao INMET e a segunda a outra instituição. Segundo os metadados do Agritempo, em seu banco só constam estações sob responsabilidade do INMET e da Epagri (Tabela 3), com os quais não há nenhuma correspondência de coordenadas geográficas.

Para ilustrar de forma resumida e objetiva os três tipos de problemas cadastrais apresentados, foi feito um estudo de caso da estação de Campos Novos. A análise de vizinhança demonstrou que num raio de $2,5 \mathrm{~km}$ podem estar estações com códigos iguais e coordenadas diferentes, códigos diferentes e coordenadas iguais, e até estações sem código (Fig. 3, Tabela 6).

A estação 83887 do INMET está cadastrada nos bancos do Agritempo e da Epagri. No banco do Agritempo ela possui o mesmo código do INMET, porém suas coordenadas foram arredondadas e, no caso da longitude, alterada. Com isso, ela está posicionada $1.800 \mathrm{~m}$ a nordeste da localização fornecida pelo INMET e a $2.417,5 \mathrm{~m}$ da localização da estação identificada no aerolevantamento (SDS, 2012). No banco da Epagri ela teve o código alterado para 94 e seu código original (83887) foi armazenado em um campo de código complementar. A latitude da estação 83887 no banco da Epagri difere da latitude fornecida pelo
INMET, causando um deslocamento de $500 \mathrm{~m}$ para o sul. A estação contida no banco da Epagri que possui a mesma coordenada da estação 83887 do INMET é a 2007, que tem o código complementar 7 e está sob responsabilidade da Tractebel. Nos bancos do INMET e do Agritempo, a estação 83887 está sob responsabilidade do INMET. No banco da Epagri a sua responsabilidade é atribuída à Epagri e ao INMET. Nenhum dos processos associados a essas mudanças e/ou diferenças está documentado nos metadados de nenhuma das quatro instituições.

Ainda num raio de $2,5 \mathrm{~km}$ da estação de Campos Novos, no banco da Epagri, há três estações com a mesma localização (Códigos 469, 1010 e 1048) que estão sob responsabilidade da Epagri, da Enercan e da Epagri/Ciram. A estação 1010 possui um código complementar (2751002) com formato semelhante ao código dado pela ANA às suas estações, porém a estação que consta no banco da ANA com código 2751002 está localizada $28 \mathrm{~km}$ a sudoeste, também sob responsabilidade da Enercan. A estação da ANA que está dentro da área coberta pelo raio de $2,5 \mathrm{~km}$ das estações de Campos Novos é a estação 2751036, cuja responsabilidade é do Consórcio Machadinho.

Esse exemplo ilustrou a dificuldade que o usuário tem no momento de escolher um conjunto de estações para gerar uma superfície contínua, considerando apenas os metadados cadastrais. A variabilidade espacial causada pela desigualdade da posição geográfica entre os bancos de

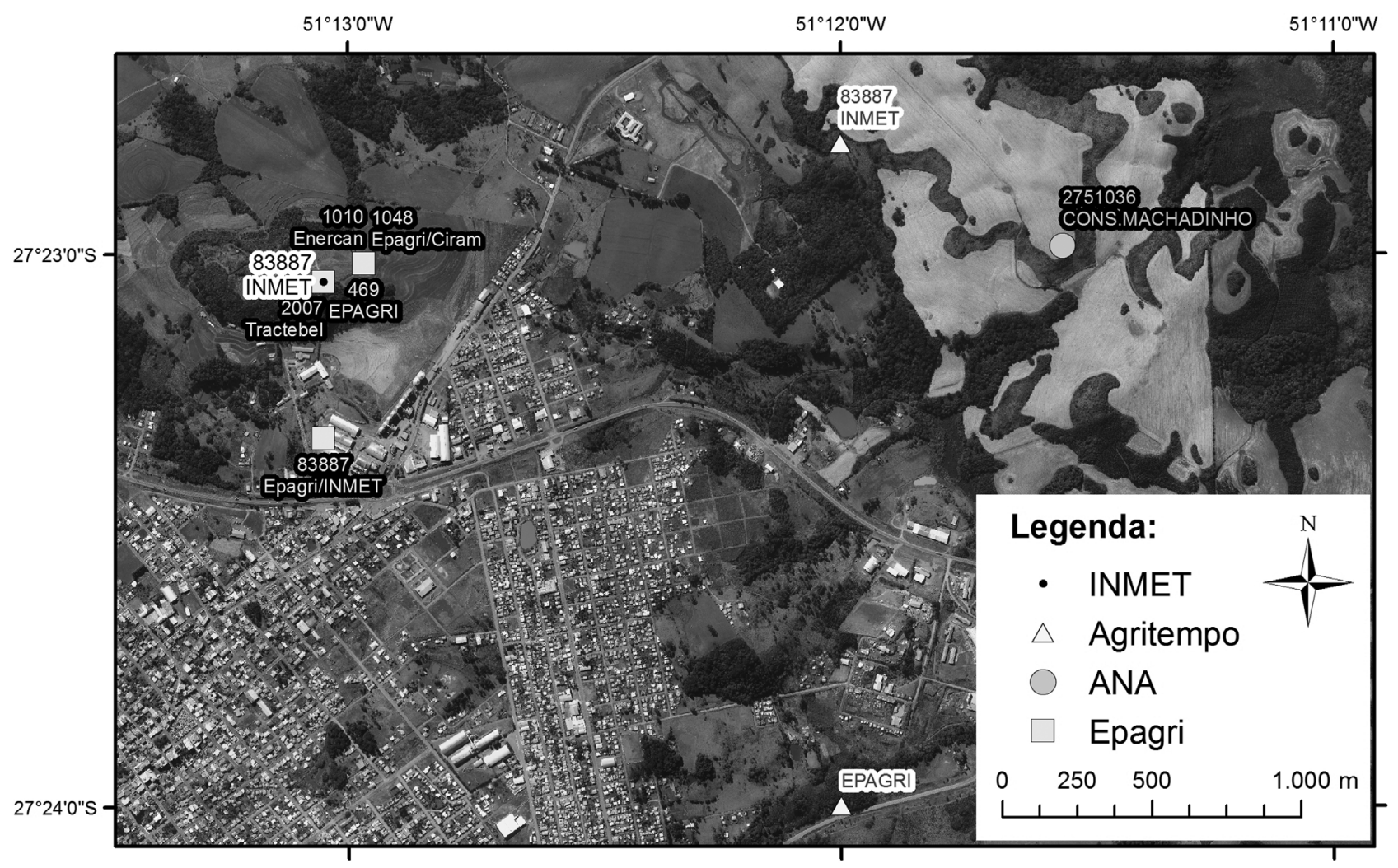

Figura 3 - Mapa das estações meteorológicas do INMET, do Agritempo, da ANA e da Epagri com códigos iguais e coordenadas diferentes, com códigos diferentes e coordenadas iguais e sem códigos, na região de Campos Novos. 
Tabela 6 - Resumo comparativo dos metadados código, código complementar, posição geográfica, instituição responsável e distância do local da estação identificado no aerolevantamento de Santa Catarina (SDS, 2012), para as coordenadas da estação de Campos Novos disponíveis nos bancos do INMET, do Agritempo, da ANA e da Epagri em um raio de 2,5 km de cada estação.

\begin{tabular}{|c|c|c|c|c|c|c|c|}
\hline Banco & Código & Código compl. & Lat. & Long. & Alt. & Responsável & Dist. Aero \\
\hline INMET & 83887 & & $-27,384167$ & $-51,2175$ & 931 & INMET & 147,6 \\
\hline Agritempo & & & $-27,4$ & $-51,2$ & 902 & EPAGRI & 2417,5 \\
\hline Agritempo & 83887 & & $-27,38$ & $-51,5$ & 931 & INMET & 1665,3 \\
\hline ANA & 2751036 & & $-27,3831$ & $-51,1925$ & 961 & Cons. Machadinho & 2338,3 \\
\hline Epagri & 94 & 83887 & $-27,388889$ & $-51,2175$ & 950 & Epagri/INMET & 590,3 \\
\hline Epagri & 469 & & $-27,383611$ & $-51,216111$ & 965 & Epagri & 27,7 \\
\hline Epagri & 1010 & 2751002 & $-27,383611$ & $-51,216111$ & 965 & Enercan & 27,7 \\
\hline Epagri & 1048 & & $-27,383611$ & $-51,216111$ & 965 & Epagri/Ciram & 27,7 \\
\hline Epagri & 2007 & 7 & $-27,384167$ & $-51,2175$ & 961 & Tractebel & 147,6 \\
\hline
\end{tabular}

dados levanta dúvida sobre a verdadeira posição geográfica da estação. Isso é agravado pela incerteza a respeito da instituição responsável por aquela estação e pela precariedade das informações dos metadados gerenciais, que aumenta mais a insegurança em relação ao acesso aos metadados corretos e a dificuldade no processo decisório de seleção das estações.

Outro problema relacionado ao desconhecimento e falta de precisão da coordenada é a variabilidade da altitude. Para demonstrá-lo utilizou-se a estação de São Joaquim (83920 do INMET), que está presente em todos os bancos com os metadados coincidentes (Tabela 7) e o modelo digital de terreno (SDS, 2012).

De acordo com os valores de altitude que constam nos bancos de dados, a estação pode estar localizada a uma altitude entre $1.370 \mathrm{~m}$ (Epagri) e $1.415 \mathrm{~m}$ (INMET), com uma variação de $45 \mathrm{~m}$. Considerando a posição dada pelas coordenadas disponíveis nos quatro bancos e a precisão de 2,5 km, a estação pode estar localizada em uma área de 3858,8 ha (Fig. 4).

Nessa área houve uma variação de altitude de 283,1 m com a menor altitude sendo $1199,6 \mathrm{~m}$ e a maior altitude $1482,7 \mathrm{~m}$. Essa diferença representa uma variação de aproximadamente $1,5^{\circ} \mathrm{C}$ de temperatura média anual segundo a equação de regressão para o Estado de Santa Catarina (Massignan e Pandolfo, 2006). Além disso, essa variação de altitude pode induzir erros nas equações de regressão entre a temperatura e a posição geográfica (latitude, longitude e altitude) utilizadas em muitos estudos climatológicos (Pandolfo, et al., 2002; Massignan e Pandolfo, 2006; Ra- mos, et al., 2009; Alvares, et al., 2013). Esse exemplo demonstrou que o desconhecimento acerca da precisão do posicionamento geográfico pode induzir a erros de uso e interpretação de dados difíceis de ser mensurados.

Para que os problemas identificados nos metadados das estações meteorológicas do Estado de Santa Catarina sejam solucionados, sugere-se que as instituições responsáveis pela operação e manutenção das estações adotem o padrão da WMO (WMO, 2015²), em vigor a partir de 2016.

\section{Conclusões}

Os metadados do INMET, ANA, Agritempo e da Epagri disponíveis para as estações meteorológicas localizadas no Estado de Santa Catarina não atendem integralmente às recomendações da WMO. Entre os metadados disponíveis pelas quatro instituições há problemas na codificação e no processo de georreferenciamento das estações. Há pouca clareza entre as instituições mantenedoras dos bancos de dados sobre quem são as instituições responsáveis pelas estações. Há divergência de informações nos metadados das estações que constam simultaneamente nos bancos de dados de mais de uma instituição. A variabilidade espacial constatada apenas em função da precisão dada pelo formato de disponibilização da posição geográfica (latitude, longitude e altitude) é responsável por erros significativos de estimativa de temperatura através de equações de regressão. A disponibilização dos metadados das estações meteorológicas, com exatidão e clareza, pelas instituições responsáveis pelas redes de estações meteorológicas no Brasil deve seguir, ao menos, os padrões da WMO.

Tabela 7 - Metadados, código, código complementar, posição geográfica e instituição responsável da estação de São Joaquim.

\begin{tabular}{|c|c|c|c|c|c|c|}
\hline Banco & Código & Código compl. & Lat. & Long. & Alt. & Responsável \\
\hline INMET & 83920 & & $-28,27583$ & $-49,934617$ & 1415 & INMET \\
\hline Agritempo & 83920 & & $-28,3$ & $-49,93$ & 1329 & INMET \\
\hline ANA & 2849014 & 83920 & $-28,2744$ & $-49,9306$ & 1408 & INMET \\
\hline Epagri & 83920 & 83920 & $-28,289444$ & $-49,943611$ & 1370 & Epagri/Inmet \\
\hline
\end{tabular}




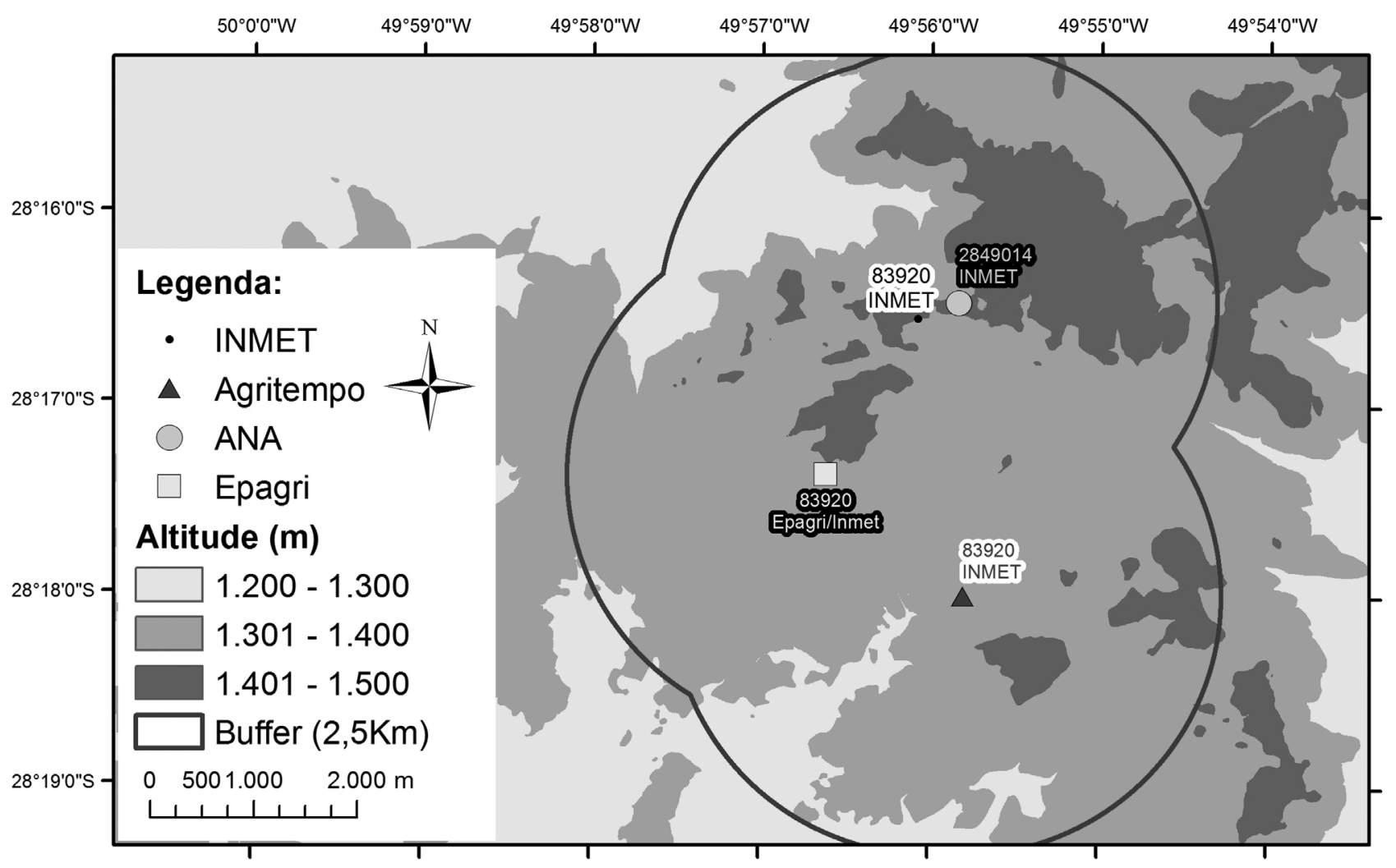

Figura 4 - Mapa da variação de altitude num raio de 2,5 km da estação 83920 do INMET, cadastrada nos bancos do INMET, do Agritempo, da ANA, da Epagri.

A segurança dos pesquisadores em climatologia no uso dos dados gerados por essas redes depende diretamente da qualidade dos metadados.

\section{Referências}

AGRITEMPO-Sistema de Monitoramento Agrometeorológico. Estações meteorológicas para o estado de Santa Catarina. Disponível em: http://www.agritempo.gov.br/agritempo/jsp/Estacao/index.jsp?siglaUF=SC. Acesso em: 29 de julho de 2015.

ALVARES, C.A.; STAPE, J.L.; SENTELHAS, P.C.; GONÇALVES, J.L.M. Modeling monthly mean air temperature for Brazil. Theoretical and Applied Climatology, v. 113, n. 3-4, p.407-427, 2013.

ANA-Agência Nacional de Águas. Especificações Técnicas Plataformas de Coletas de Dados-PCDs. Superintendência de Gestão da rede Hidrometeorológica. Brasília, 21p., 2011.

ANA-Agência Nacional de Águas. Inventário das estações pluviométricas. $2^{\mathrm{a}}$ ed. Brasília, SGH, 2009. Disponível em: http://arquivos.ana.gov.br/infohidrologicas/InventariodasE stacoesPluviometricas.pdf. Acesso em: 29 de julho de 2015

ANA-Agência Nacional de Águas. HidroWeb-Sistema de Informações Hidrológicas.

Inventário Pluviométrico/Fluviométrico, 2015. Disponível em: http://hidroweb.ana.gov.br/baixar/software/Inventário.zip . Acesso em: 29 de julho de 2015.

BRASIL. Decreto no 89.817, de 20 de junho de 1984. Estabelece as Instruções Reguladoras das Normas Técnicas da Carto- grafia Nacional. Diário Oficia da União, Brasília, DF, n. 120, 1984.

BRASIL. Decreto n ${ }^{\circ} 77.410$, de 12 de abril de 1976. Codifica as estações hidrológicas do país e dá outras providências. Diário Oficia da União, Brasília, DF, seção 1, p. 4754, 1976.

BRASIL $^{2}$. Ministério de Estado das Minas e Energia. Portaria $\mathbf{n}^{\mathbf{0}}$ 447, de 20 de abril de 1976. 1976. Disponível em http://infoener.iee.usp.br/legislacao/legisla nac/eletrico/lei s/portaria_447.html Acesso em 06 de fevereiro de 2017.

CAMERA, C.; BRUGGEMAN, A.; HADJINICOLAOU, P.; PASHIARDIS, S.; LANGE, M.A. Evaluation of interpolation techniques for the creation of gridded daily precipitation (1X1 km2) Cyprus, 1980-2010. Journal of Geophysical Research: Atmospheres, v. 119, n. 2, p. 693-712, 2014.

CASTRO, F.; PEZZOPANE, R.C.; PEZZOPABE, J.; XAVIER, A. Avaliação do desempenho dos diferentes métodos de interpoladores para parâmetros do balanço hídrico climatológico. Revista Brasileira de Engenharia Agrícola e Ambiental, Campina Grande, v. 14, n. 8, p.871-880, 2010.

CLIMATEMPO. Climatempo News Ao Vivo. Disponível em: http://www.climatempo.com.br/videos/ao-vivo . Acesso em: 10 de setembro de 2015.

CUNHA, G.; HASS, J.; MALUFI, J.; CARAMORI, P.; ASSAD, E.; BRAGA, H.; ZULLO, J.; LAZZAROTTO, C.; GONÇALVES, S.; WREGE, M.; BRUNETTA, D.; DOTTO, S.; PINTO, H.; BRUNINI, O.; THOMÉ, V.; ZAMPIERI, S.; PASINATO, A.; PIMENTEL, M.; PANDOLFO, C. Zoneamento agrícola e época de semeadura para o trigo no Brasil. Revista Brasileira de Agrometeorologia, Passo Fundo, v. 9, n. 3, p. 400-414, 2001. 
EPAGRI/CIRAM - Empresa de Pesquisa Agropecuária e Extensão Rural de Santa Catarina. Centro de Informações de Recursos Ambientais e de Hidrometeorologia de Santa Catarina. Monitoramento online. Disponível em: http://ciram.epagri.sc.gov.br/index.php?option=com content\&view $=$ article $\&$ id $=98 \&$ Itemid $=198$. Acesso em: 29 de julho de 2015

HERRMANN, M. Atlas de Desastres Naturais do Estado de Santa Catarina. Florianópolis. IOESC, 136p. 2006. Disponível

em http://www.ceped.ufsc.br/wp-content/uploads/2006/01/Atlas_Ceped.pdf Acesso em 06 de fevereiro de 2017.

INMET - Instituto Nacional de Meteorologia, Brasília, DF, Brasil. Disponível em: http://www.inmet.gov.br/portal/index.php?r=tempo2/mapasPrecipitacao. Acesso em: $10 \mathrm{de}$ setembro de 2015.

INMET $^{2}$ - Instituto Nacional de Meteorologia. Estação Meteorológica de Observação de Superfície Automática, Brasília, DF, Brasil. Disponível em: http://www.inmet.gov.br/portal/index.php? $r=$ estacoes/mapaEstacoes . Acesso em: 29 de julho de 2015.

INMET $^{3}$ - Instituto Nacional de Meteorologia. Estação Meteorológica de Observação de Superfície Automática, Brasília, DF, Brasil. Disponível em: http://www.inmet.gov.br/portal/index.php? $r=$ estacoes/estacoesAutomaticas . Acesso em: 29 de julho de 2015.

INMET $^{4}$ - Instituto Nacional de Meteorologia. Estação Meteorológica de Observação de Superfície Convencional. Brasília, DF, Brasil. Disponível em: http://www.inmet.gov.br/portal/index.php? $\mathrm{r}=$ estacoes/estacoesConvencionais . Acesso em: 29 de julho de 2015.

INMET $^{5}$ - Instituto Nacional de Meteorologia. Banco de Dados Meteorológicos para Ensino e Pesquisa - BDMEP. Brasília, DF, Brasil. Disponível em: http://www.inmet.gov.br/portal/index.php?r=bdmep/bdmep . Acesso em: 29 de julho de 2015.

INPE/CPTEC - Instituto Nacional de Pesquisas Espaciais. Centro de Previsão de Tempo e Estudos Climáticos. Cachoeira Paulista, SP, Brasil. Disponível em: http://previsaonumerica.cptec.inpe.br/ Acesso em: 10 de setembro de 2015

JONES, P.D.; LISTER, D.H.; HARPHAM, C.; RUSTICUCCI, M.; PENALBA, O. Construction of a daily precipitation grid for southeastern South America for the period 1961-2000. International Journal of Climatology, v. 33, n. 11, p. 2508-2519, 2012

LUCAS, T.P.B.; PLEC, D.; ABREU, M., L.; PARIZZI, M.G. Identificação de interpoladores adequados a dados de chuva a partir de parâmetros estatísticos. Curitiba. Associação Brasileira de Climatologia, Revista Brasileira de Climatologia, v. 13, p. 7-21, 2013.

MASSIGNAM, A.M. e PANDOLFO, C. Estimativa das médias das temperaturas máximas, médias e mínimas do ar decendiais e anuais do Estado de Santa Catarina. Empresa de Pesquisa Agropecuária e Extensão Rural de Santa Catarina Epagri. Série Documentos n. 224, 26p., 2006.

MASSIGNAM, A.M.; PANDOLFO, C.; HECK, T.; VIANNA, L.F.; ZAMPIERI, S.; JUSTEN, J. Zoneamento climático da pupunha (Bactris gasipaes) para o Estado de Santa Catarina.
Revista Agropecuária Catarinense. Florianópolis, v. 27, n. 1, p. $86-90,2014$.

NOAA - Nacional Oceanic and Atmospheric Observation. National Weather Service, Silver Spring, MD, USA. Disponível em: http://www.weather.gov/forecastmaps . Acesso em: 10 de setembro de 2015 .

PANDOLFO, C.; BRAGA, H.J.; SILVA JÚNIOR, V.P.; MASSIGNAN, A.M.; PEREIRA, E.S.; THOMÉ, V.M.R; VALCI, F.V. Atlas climatológico do Estado de Santa Catarina. Florianópolis: Epagri, 2002. CD-ROM.

PERIN, E.; VIANNA, L.F.; RICCE, W.; MASSIGNAM, A.: PANDOLFO, C. Interpolação das variáveis climáticas temperatura do ar e precipitação: revisão dos métodos mais eficientes. Revista Geografia, Rio Claro, v. 40, n. 1, p. 269-289, 2015.

RAMOS, A.M.; SANTOS, L.A.R.; FORTES, L.T.G. Normais Climatológicas do Brasil 1961-1990. Instituto Nacional de Meteorologia-INMET, Brasília, DF, 465p. 2009.

RICCE, W.; CARVALHO, S.; CARAMORI, P.; ROBERTO, S. Zoneamento agroclimático da cultura da videira no Estado do Paraná. Londrina, SEMINA: Ciências Agrárias, v. 35, n. 4, p. 2327-2336, 2014.

SDS - Secretaria de Estado do Desenvolvimento Sustentável de Santa Catarina. Relatório final de produção do aerolevantamento e modelo digital de terreno de Santa Catarina. Florianópolis, 218 p., 2012.

SILVA, K.R.; CECÍLIO, R.A.; XAVIER, A.C.; PEZZOPANE, J.R.M.; GARCIA, G.O. Interpolação espacial da precipitação no Estado do Espírito Santo. FLORAM-Floresta e Ambiente, Rio de Janeiro, v. 18, n. 4, p. 417-427, 2011.

WERGE, M.S.; STEINMETZ, S.; JÚNIOR, C.R.; ALMEIDA, I.R. Atlas Climatológico da Região Sul do Brasil. Estados do Paraná, Santa Catarina e Rio Grande do Sul. Embrapa Clima Temperado, Pelotas, RS, 336p. 2011.

WMO - World Meteorological Organization. Guidelines on Climate Metadata and homogenization: WMO $n^{\circ}$. 1186, Genebra, Suíça, 2003.

WMO - World Meteorological Organization. Guide to the Global Observing System, WMO $\mathrm{n}^{\circ}$. 488, $3^{\mathrm{a}}$ ed., Genebra, Suíça, 2007.

WMO - World Meteorological Organization. Guide to Meteorological Instruments and Methods of Observation, WMO nº. 8. Genebra, Suíça, 2008.

WMO - World Meteorological Organization. Manual on Codes: international codes, vol. I. Part A-alphanumeric codes. WMO n. 306, 2011 ed. rev., Genebra, Suíça, 2014.

WMO - World Meteorological Organization. WMO Integrated Global Observing System. Disponível em: www.wmo.int/wigos Acesso em: 10 de setembro de 2015.

$\mathrm{WMO}^{2}$ - World Meteorological Organization. WIGOS Metadata Standard. WMO Thecnical Regulations (WMO-NO. 49)-Manual on WIGOS. World Meteorologica Congress. Geneva, 117p. 2015. Disponível em: http://www.wmo.int/pages/prog/www/wigos/documents/Cg-17/Cg-17-d04-2-2(3)-add1-MANUAL-ON-WIG OS-approved_en.docx . Acesso em: 10 de setembro de 2015.

This is an Open Access article distributed under the terms of the Creative Commons Attribution Non-Commercial License which permits unrestricted non-commercial use, distribution, and reproduction in any medium provided the original work is properly cited. 